\title{
An Existential - Humanistic Approach to Movement: An East/West Dialogue
}

\author{
人本-存在主义取向的舞动治疗 : 中西方对话 \\ Ilene A. Serlin ${ }^{1}$ and Chloe Liu刘又嘉 ${ }^{2}$ \\ ${ }^{1}$ Union Street Health Associates, USA \\ ${ }^{2}$ Sichuan Humanistic Psychotherapy, China
}

\begin{abstract}
This article considers existential-humanistic (EH) psychotherapy in relation to concepts in Chinese culture and shows how those approaches are experienced in the body. An embodied form of EH group dance movement therapy called "KinAesthetic Imagining" can bridge West and Eastern philosophies through symbolic nonverbal communication. In the following article, the philosophical foundation and training of KinAesthetic Imagining is described. It is followed by a dialogue and observations from a student from China whose background in existential philosophy, and Yalom group therapy gave her a philosophical perspective on becoming embodied. She describes her own experience of a theme central to existential psychotherapy, death, and rebirth and how she experienced this in her body in a new and profound way.
\end{abstract}

Keywords: Existential-humanistic therapy, embodiment, existential dance movement therapy, life and death education, group psychotherapy, KinAesthetic Imagining

\section{摘要}

本文将人本-存在主义心理治疗与中国文化中的一些概念相联系，并展示这些方法在身 体上是如何被体验的。一种被称为 “动觉成象” 的具身化的人本-存在主义团体舞动治 疗，它可以通过象征性的非语言交流来连接东西方哲学。在下文中，将描述动觉成象的 哲学基础和训练。接下来会有一段精彩的中西方对话，以及一位来自中国的学生的观察 报告。她深厚的存在主义哲学背景和亚隆团体治疗经验使她在具身化时持有着一种哲学 的视角。她描述了自己对存在主义心理治疗、死亡和重生的核心主题的体验，以及她如 何以一种全新而深刻的方式在自己的身体中体验这一主题。

关键词:人本-存在主义心理治疗，具身化，人本-存在主义取向的舞动治疗，生死教育，团体心理 治疗，动觉成象

\section{Introduction}

In this article, Ilene Serlin and Chloe Liu explore the relationship between an existential approach to group psychotherapy and traditional Chinese culture and how the experience of an existential approach to group psychotherapy is amplified by bringing in the language of the body. 


\section{What is an existential-humanistic approach to movement?}

Serlin: Although an existential-humanistic (EH) approach is one that has not received much attention from dance and movement therapists (Levy, 1992), it was one of the first to have an experiential, embodied approach to psychotherapy. Hanna (1970) created the field of somatic psychology, which is now a separate field of its own. Selver and Brooks (1986) introduced body awareness at Esalen, where humanistic psychology came of age during a time of cultural freedom and exploration in America. As a reflection of the times and in contrast to Freudian and more traditional approaches, humanistic psychology emphasized personal freedom, expression and creativity.

Humanistic psychologist Bugental $(1964,1987)$ trained his students in "presence," a particular kind of energy to be embodied by the therapist. Presence has nothing to do with what the therapist says, but it is about the quality of energy that the therapist projects. The therapist must train in a type of meditative consciousness to develop a clear, focused, and empathetic awareness. The subjectivity, emotions, and caring of the therapist get communicated primarily without words. Bugental rejected the psychoanalytic model of the therapist as a blank screen and the Rogerian model of the therapist as a mirror. In his EH model, the therapist is asked to be authentic, modeling for the client how to be fully alive and human, with a full range of emotions and motivation. The human relationship is the healing agent, with the verbal and nonverbal dialogue in what Buber (1963) called an "I-thou" relationship. Dance movement therapy (DMT) also uses presence to create a holding environment. In addition, it can bring a systematic, articulated set of observations that can be integrated into the verbal therapy work (Laban, 1971).

Gestalt therapy is another form of EH therapy. My own psychotherapy training was with Dr. Laura Perls, wife of Fritz Perls and one of the co-developers of Gestalt therapy. Laura had been a dancer in Germany and was very familiar with the arts, so Gestalt as a language of process and interaction was a perfect framework for me to understand my dance therapy experience (Serlin, 1992).

\section{What is existential-humanistic psychology?}

According to a brief summary of the history of EH psychology, May (1967, 1975; May et al., 1958) is the bridge between a European phenomenology and existentialist darkness after World War II. The suffering and destruction of the war profoundly affected existential philosophers in Paris such as Simone de Beauvoir and Jean-Paul Sartre. Simone de Beauvoir, with her groundbreaking book on the empowerment of women (1997), profoundly appealed to me and to many women of my generation. European philosophers developed phenomenology, a study of the natural state of things, not reducing a person to a set of symptoms or a passive category like a patient or diagnostic category (Boss, 1963; Buber, 1963; Frankl, 1984; Heidegger, 1962; Husserl, 1931; Jaspers, 1963; Kierkegaard, 1980). 
Some faced death and came through with resilience and renewed will to live (Frank1, 1984). In the United States, Rogers $(1951,1961)$ developed "client-centered" therapy, in which the therapist was nondirective and met each client with unconditional positive regard.

Maslow (1954) stressed the "higher reaches" of human nature, especially "peak experiences." However, May thought that the unconditional positive regard of Rogers was too naïve and saw human nature and reality as darker. May and Bugental also placed more value on the role of the unconscious and early childhood experiences than Rogers, and their theories were sometimes called "existential-depth." However, the term "existential-humanistic psychologist" also does convey both depths and heights of human experience.

\section{What is existential-humanistic psychology and how does it relate to Chinese culture?}

Existential philosophies have similarities with some aspects of Chinese poetry, literature, and philosophies. Both existential philosophies and Chinese culture concern themselves with the fundamental themes of life: suffering and finding a way out of suffering (Hoffman et al, 2009; Hoffman et al, 2019; Lu Xun, 1961; Yang, 2016). From an existential point of view, we need to confront death (our own mortality) in order to live fully (Bakewell, 2017). The emphasis from an existential approach is to be fully human, fully present in the moment. With a balance of body, emotion, energy, and spirit, one can make wise choices and create a meaningful life. From a Chinese perspective, all three major Chinese philosophies, Taoism, Confucianism, and Buddhism, contain strong existential themes (Yang, 2017).

There was a growing interest in existentialism among scholars and psychotherapists in China when China opened to the West in the 1980s and 1990s. Nietzsche, Heidegger, Kierkegaard, and others were read in Chinese universities. Lu Xun, a philosopher and writer, is called the "Nietzsche of China" (Wang, 2019, p. 580). The heroic warriors described by Western writers, from Socrates to Christ ("warriors of the spirit"), were reflected Chinese characters called the "backbones of China" (Wang, 2019, p. 580).

Ro explored these issues of similarities and differences between an EH psychology and Chinese culture, and a conference was held in Nanjing in 2010. The First International Conference on Existential Psychology, titled "An Intellectual Dialogue between East and West: How to Face Suffering and Create Value of Life," was organized by American and Chinese existential therapists Louis Hoffman, Mark Yang, and Xuefu Wang and hosted by Nanjing Xiao Zhuang University, the China Institute of Psychology (CIP), and the ZhiMian Institute for Psychotherapy.

I was a part of a group of more than 40 existential psychology experts from the United States, China, Europe, Greece, and Southeast Asia who assembled in Nanjing to engage in the mutual exploration and dialogues on the basic themes between existential psychology/ psychotherapy and Chinese philosophy/cultural psychology. During this time, training programs in Yalom group therapy were established at CIP and an indigenous form of EH psychotherapy was established at the ZhiMian Institute and at CIP. 
My own interest in the cultural exchange came from years of studying and practicing Tibetan Buddhism, mindfulness practices, and existential psychology. Folk dance and travels through many parts of the world taught me that dance and nonverbal communication can be powerful methods of communication and mutual understanding. In an age of people's migration, dislocation, and trauma, movement can help people find stability and resilience within themselves. Here was an opportunity to explore these interfaces between Western and Eastern psychologies through verbal and nonverbal modalities.

After the conference in Nanjing, I was invited to lead a workshop at CIP in Beijing on an EH approach to movement therapy. After the workshop, I was asked to start a 2-year training program. I brought in Dr. Marcia Leventhal (Leventhal, 2008), a fellow student of Irmgard Bartenieff, to help organize the training. We are now in our seventh year, and students are already beginning to lead groups under supervision. Since we were not training dance therapists but rather therapists who wanted to learn to use the body as a medium for expression and were already credentialled, we called the training Whole Person Health: The Art of Embodiment. The students go through the training as a strongly bonded cohort group, experiencing personal transformation as they understand themselves and others through movement. Their process group follows a structure based on a Gestalt and Yalom (1985) group therapy model. This combination of verbal and nonverbal existential approaches to group psychotherapy was presented at the American Psychological Association meeting with Dr. Ruth Josselson of the Yalom Institute as a dialogue between East and West in 2015.

\section{What is the art of embodiment?}

The art of embodiment is a therapeutic process in which the body is a primary way of becoming aware of our most authentic self (Jourard, 1976) and of bringing this way of knowing into our work with clients. We learn how to perceive, access, and uncover our authentic selves as expressed through our emotions and physical expression (Criswell, 1989; Criswell \& Serlin, 2014). We become able to discern how the personality is developed and expressed with and through use of expressive body movement directly. We learn to read and interpret the nonverbal communication of others and how to use this understanding in our everyday lives and apply it in our own work.

\section{KinAesthetic Imagining}

The training program begins with KinAesthetic Imagining (Serlin, 1996), a process by which the moving body creates meaning through images that can be understood like dream images. We start with the body as instrument, cultivating qualities of embodiment, and kinesthetic intelligence. Participants learn how to ground themselves, how to tune into their own bodies and those of others. They practice creating a safe space (usually a circle), mirroring, picking up movement cues, and supporting the emerging images. They learn a language of movement that describes nonverbal communication in terms of time, weigh, space, and flow. This language helps them articulate how they are experienced in relationship with others and in their everyday lives. Participants learned to ground themselves, practice relaxation, improvise, and growing more at home and 
confident in their bodies. They understand their movements in terms of archetypal figures and symbols as well as the group process in terms of the existential dimensions of freedom and fate, being alone vs. being with others, life and death, and meaning vs. meaninglessness (Yalom, 1985).

KinAesthetic Imagining is an existential/depth form of movement in which bodily based images create a nonverbal narrative or text with metaphoric, symbolic, and transformative levels of meaning (Serlin, 1996). It is compounded from the Greek word kinesthesia, which means "sensation of movement" (Greek: kinae [movement] and easthesia [sensation]). "Imagining" is an active process by which images are generated and formed. Therefore, KinAesthetic Imagining is the process by which the perceptions arising from moving muscles generate and make explicit imaginative structures of consciousness. As embodied narrative or action poesis, KinAesthetic Imagining is a dynamic process by which people often compose themselves and form their lives. Since grief often stays stuck in the body, moving through the images and feeling the feelings in the body is crucial for healing (Serlin, 2014). Based on Ricoeur's (1976) linguistic theory, KinAesthetic Imagining first establishes a movement process as a nonverbal text with levels of meaning that include the phenomenological (metaphor, conscious), archeological (symbols, stories, archetypal, myths, unconscious), and teleological (future, spiritual, ritual, numinous), and that is dialogical and relational with a mover and a witness or witnesses.

KinAesthetic Imagining has a simple three-part structure that includes check-in and warm-up (the lived body), amplification (articulate body), and making meaning (action hermeneutics).

Check-in and warm-up. Use of breath, sound, stretching, and circle dance movements will warm up the body, bring body awareness and consciousness to self and others, create the container, and mobilize healing energies.

Amplification. Repetition and deepening the emerging themes help explore images and emotions that arise from individual, dyadic, and group movements. Participants have an opportunity to develop their own personal healing images, stories, and mythologies.

Making meaning (action hermeneutics). This is a time to wind down, internalize the imagery, represent it in paint or words, reflect on its meaning, let it go, and make a transition into real life.

\section{Existential themes}

The existential themes seemed to resonate with many members, especially the theme of freedom and fate (or constriction). Some yearned for freedom, some felt constrained by their fate. Embodying these themes through the Laban qualities of "free" and "bound" helped group members feel and express their responses to these themes. One group developed and performed a dance about freedom and fate that told a Chinese version of the story of Romeo and Juliet. Unlike the Western version where the protagonists die, the Chinese version contains an afterlife where the lovers are reincarnated as butterflies. Other students, discovering new freedom, expressed a yearning for authenticity and the 
need to find meaning in life. Life for many was an effort to balance the Taoist influence of process and flow and individual development with the Confucian influence of strict roles, hierarchies, and restraint. One woman shouted, "I'm so tired of being Confucian good girl, good daughter, good mother...I want to be me! But I have no idea where to start—can you help me?"

All participants experience the terror of the blank page, the void or the unformed movement, but follow May's (1975) Courage to Create with the "Courage to Move" in the face of the void (Serlin, 2012) and commit themselves to live deeply. Existential issues that arise in the group include the following: The life of a group goes through stages of existential responsibility, confrontation with mortality, freedom and fate, death and rebirth; each individual goes through existential choices about commitment, meaning, joining in groups; verbal and nonverbal relationships in the group are a reflection of relationships in the family, the community and the larger world; congruence between verbal and nonverbal expression in groups is a sign of psychological health, and participants in dance therapy can learn to experience and change how they move in the group and in life.

\section{Movement choirs}

Movement choirs bring DMT into a new setting (Bartenieff, 1980). Figure 1 shows the movement choir as an opening or closing ritual (Serlin, 1993) used to close the conference on Existential Psychology at Fudan University, Shanghai, in 2012.

\section{The dance of transcendence}

Further explorations about the relationship between existential psychotherapy and Chinese philosophy and the role of embodiment took place in a conversation between Ilene Serlin and Chloe Liu, a student at the CIP. Ilene asked the students to keep a journal and reflect on their experiences. Chloe came into the group with obvious skills in group leadership, but for her, the added dimension of the body brought new insight. Her reflections are below, as are her answers to the questions I posed.

\section{We approach the life wisdom of "being-towards-death" by dance therapy with an existential-humanistic approach}

Serlin: Do you think existentialism is related to Chinese philosophy? If so, how?

Liu: In traditional Chinese philosophy, the ultimate goal of life, or ultimate concern, is the question of "settle down and get on with one's pursuit." Everyone has her or his own understanding and cognition of life and the world, so that everything in life and the world has different meaning and value for different people. All the awareness and understanding of the life and world, to a certain extent, make the different meanings of the life and world to different people, which constitute a certain "state" of themselves. It is very similar to Sartre's existentialism, which is the living and central fact of life. As an EH psychotherapist, when I delivered psychological service to clients, I found that existential and humanistic psychology, which I have been practicing for years, is 


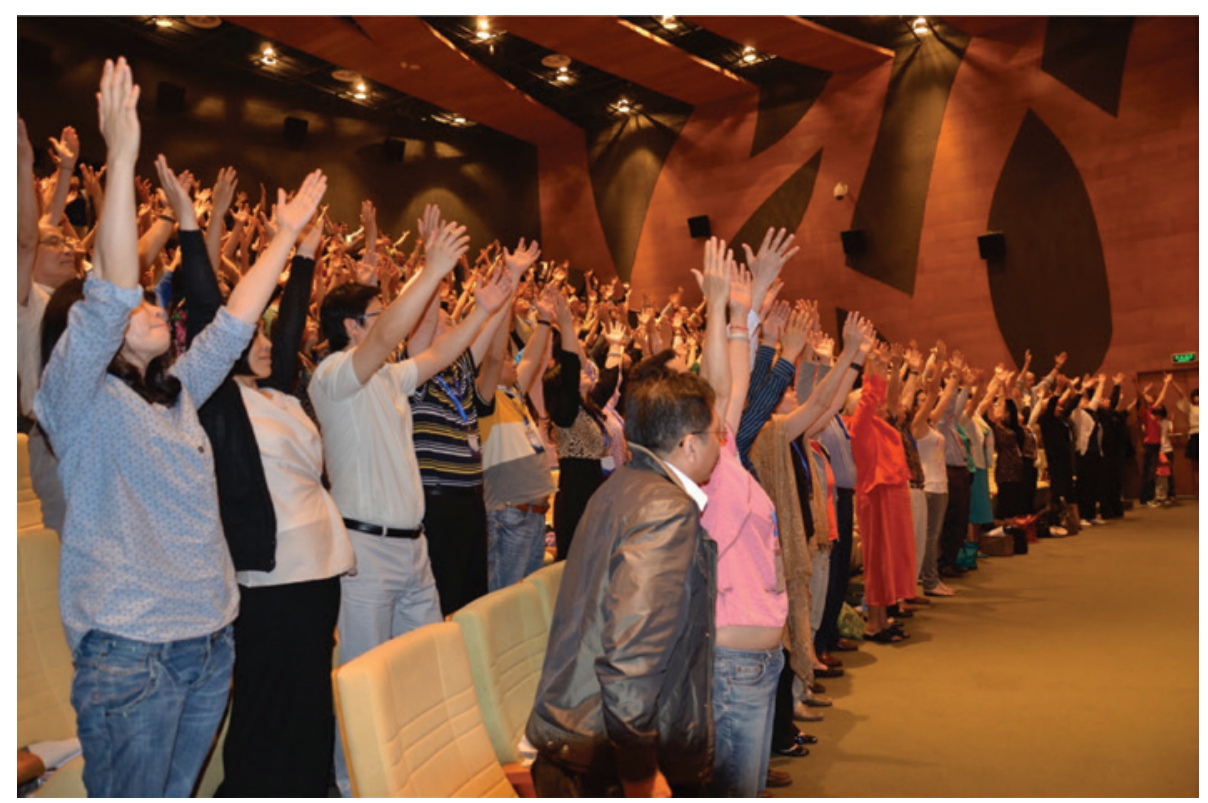

Figure 1 | Movement choir at Fudan University, 2012.

operationally effective and compatible with clients having life-and-death-related issues. The four ultimate restrictions of human existence-death, freedom without root, isolation, and meaninglessness have doomed life with suffering and inner conflict. Why do we still struggle to live? If we think it is not necessary to live, what kind of experience is death?

These answers can only be obtained through in-depth personal introspection. Yalom (2012) said that these introspection processes require people to separate from the daily trivia that fills their world, and they may be catalyzed by emergency or boundary experiences facing one's own death. Therefore, I began to search for the approach in China that integrates different perspectives from existentialism, existential psychology, humanistic psychology, and metaverbal expressive art therapy.

Serlin: Can you give us an example of the body bringing in a whole new way of knowing, of being and of perceiving? How is an existential moment in therapy experienced in the body?

Liu: I want to start from "existential issues" and transformation I experienced in the dancing group at the CIP. The experience has given me deep inspiration about how people develop profound self-reflection and insight through acute observation, wholeperson companionship, and humanistic care. They develop the attitude and stance of dancing therapists and sincerely and poetically connect with their own experience in the treatment field to integrate body, mind, and spirit. Finally, they gain awareness of their own existence and death. 
One morning, I asked Ilene how to experience death in movement? What kind of experience is death, how terrible is it? What is it after death, and what will I do? I am very curious. I was eager to get the answer from movement and Ilene, but the teacher did not give me a clear verbal answer. I do not remember how Ilene led and what the group did in the structure, in the next dancing link. I was totally immersed in the inner experience. At that time, one of my hands was held by the other hand. I followed the lead of that hand and danced. This hand was not someone's hand. It was the energy that led me to follow. The energy of the group was transmitted to me through this hand. All of a sudden, my consciousness turned to my empty hand. I was a little flustered. I felt that this hand should also grasp the hand of another person. It did not matter who that person was, but it just let me feel that I was integrated with everyone. My inner needs were expressed through the flustered search of this hand. At this time, a hand was handed to me in time. The timing was just right, and the intensity was proper. At the moment when I needed it, I held a hand. I experienced that it was like when I was about to lose power, I was connected to the power supply, and I was able to live again. I opened my eyes and found it was Ilene. I felt a gentle holding and deep stare. I was just like a little baby when hungry; I was held by one hand to the breast and drank sweet milk. I closed my eyes and continued to immerse myself in the nourished life. I started to grow again from the stagnant state. I had many desires, aspirations and hopes for the future. However, I have also been feeling that I was thrown into an empty space, just like an astronaut, shuttling through space in a spaceship. Suddenly, I was thrown out of the cabin. With the separation from mankind, all future possibilities came to an abrupt end. The spirit was still there, but it floated alone in endless space and time again. I know I have experienced death, and I have also experienced my nostalgia for life. After experiencing all this, I discovered that the hand I was holding had been released.

In dance therapy, the miraculous experience of death made me realize that I chose to live, because I long for the diverse possibilities of the future. I was lucky to meet death by chance, and I experienced that life is like "possible possibility of the future" (Kierkegaard, 1980) and death is like "possible impossibility of the future" (Heidegger, 1962). I know that only when we are alive can it be possible to realize infinite possibilities even in our limited life.

The body and the mind are the carriers of the soul. Dance therapy combines the body, the mind, and the spirit closely, embodying the "whole-person" experience from multiple dimensions, including ordinary and nonordinary state of consciousness, self-actualization, diverse worldviews and perspectives, direct experience, and analytical intellect. Dancing should have a very important position in the journey of human being-towards-death awakening and healing, because it comes from the body wisdom of human instinct, and it touches and expresses a complete and complicated person from all levels of body, mind, and spirit. These are the three most essential dimensions of human beings and are the core and cornerstone of all treatments and changes.

All life will eventually die, and the tension between the awareness of dying and the will to live is with us all our lives. Death is the original source of human anxiety and the most stubborn denial of the human defense system. However, life and death depend 
on each other and exist at the same time. Death always flows under the surface of life, strongly affecting our experience and behavior.

As I experienced death awareness in dancing, I was thrown from a safe spaceship into a universe without sound and light. This is like experiencing birth-a baby is thrown from its symbiotic state with its mother into this complicated and dangerous strange world from the womb and then lingers for the rest of its life in the choice of finding self-independence and connecting with others.

The therapeutic purpose of an EH orientation, therefore, is to help people peel off layers of defense in order to discover their authentic selves and the truth of life. When people explore the truth and define the authentic selves, they will definitely touch pain, suffering, fear, or shame (Koff-Chapin, 1996). Dance therapy cultivates the trust and application of intuition and nature, listens to organismic guidance, abd reveals and discovers deeper truths that may not be available by other therapies (Serlin, 2019).

"Meaning" refers to the concepts underneath a superficial phenomenon. The Sutra of Consummate Enlightenment has the following paragraph: "And this could be compared to drilling wood for fire: By the use of two pieces of wood, each as the Reciprocal Cause for the other, the fire could then be produced; wherein the wood is to be incinerated; finally on the extinguished embers' being blown away, the smoke would vanish into the thin air. It would be exactly the same with the cultivation on Phantasms by means of Phantasmic Dharmas: albeit all Phantasmata are eliminated, one would not be subjected to Nihilistic Extinction" (包祖晓, 2019, p. 261). The Buddha uses “wood" as metaphor to tell the people what is "being-towards-death" and why people need the meaning of life.

As therapists, how can we help our clients? Therapy, in ancient Greek therapeuticus, means "to be attentive to." As therapists, we cannot fill in the emptiness of the clients or directly tell them what the meaning of life is. Only the client can discover and create the meaning of her or his own life, and this meaning is dynamic in terms of the current experience and situation (Moon, 2011). Searching for meaning is difficult because clients may face overwhelming fear, anxiety, and existential frustration. Dancing therapists accompany their clients with their whole existence. They guide them to explore themselves with metaphors that restore trust and openness to their body experience, assisting them to embrace their pain and struggle for life.

Although the life significance of everyone is unique, the significance cannot be produced in a personal, isolated vacuum (Moon, 2011). Life significance is not entirely an internal phenomenon and exists in the relationship of the individual and her or his world. A dance therapy group can explore the world with many different interpretations at the same time and produce dynamic and variable personal meanings for each group member. With this strong sense of themselves, they may not be completely hopeless and helpless to face existential frustrations. People become participants and viewers of their own experience process, not the supervisors of their experience. Their life will be reconstructed as an integrative whole, a one-piece story and life journey, and it will continue in the future.

The humanistic existential approach of dance therapy emphasizes the cultivation and unfolding of the bodily kinesthetic intelligence, enabling access to inner wisdom and knowing from a somatic sensitivity perspective (Serlin, 2019). Dancing is a kind 
of perception or feeling, a kind of life, a new view of observing things in life, and a consciousness toward the soul.

Serlin: Do you think existential psychology might be a closer fit to Chinese culture than other forms of Western psychotherapy?

Chinese philosophy is a human-centered ideological system, believing that human is a spiritual subject that "The nature of everything is what I have." That is, all nature is in communion with me.

For example, the yin and yang are a model that the faithful follow, an aid that allows each person to contemplate the state of her or his life. More a mode of living than an actual theology, Taoism asks that each person to focus on the world around her or him in order to understand the inner harmonies of the universe. Chinese philosophy emphasizes the dynamic change process of individual experience, which is similar to the EH psychotherapy that emphasizes people's trust in experience, integrating the whole person and experience.

It is generally believed in Chinese philosophy that the mind is a dynamic process of self-realization whose ultimate goal has different expressions in the different philosophical systems. Confucianism calls it the "saint." Taoism calls it "natural." Buddha calls it "nirvana."

\section{Conclusion}

Grounded in both Western and Eastern culture, a humanistic-existential approach to therapy focuses on the inevitable fact of death with the challenge to actively create, choose, and commit to a life of authenticity and meaning. The art of embodiment brings a strong experiential component in exploring these themes in a group process context. Using KinAesthetic Imagining, group members can explore existential themes of life and death, freedom and fate, being alone or in relationship, and meaning or meaninglessness.

\section{About the Authors}

Ilene A. Serlin, PhD, BC-DMT, a clinical psychologist and registered dance/movement therapist, founder and Director of Union Street Health Associates and the Arts Medicine Program at California Pacific Medical Center. She is a Fellow of the American Psychological Association, Past President and Council Representative of the Division of Humanistic Psychology of the American Psychological Association.

Chloe Liu刘入嘉, psychological consultant, served as the specialist commentator of Sichuan TV station, served as the psychological consultant of many kindergartens, primary schools and high schools in Chengdu and committed to the research and practice of humanistic existential-oriented dance therapy, introduced dance therapy into the course of "Family Spirit Inheritance" and "Life and Death Education" (a new course for people to get the life wisdom of "being-towards-death"), and started a series of practical work in China. 


\section{References}

Bakewell, S. (2017). At the existentialist cafe: Freedom, being, and apricot cocktails. Beijing: New Media Co. Bartenieff, I. (1980). Body movement: Coping with the environment. New York: Gorden \& Breach. Boss, M. (1963). Psychoanalysis and daseins analysis. New York: Basic Books.

Brooks, C. (1986). Sensory awareness: Rediscovering of experiencing through the workshops of Charlotte Selver. Great Neck, NY: Felix Morrow.

Buber, M. (1963). The way of man: According to the teachings of Hasidism. London: Vincent Stuart.

Bugental, J.F.T. (1964). The third force in psychology (basic postulates and orientation of humanistic psychology). Journal of Humanistic Psychology, 4, 19-26.

Bugental, J.F.T. (1987). The art of the psychotherapist. New York: Norton.

Criswell, E. (1989). How yoga works: An introduction to somatic yoga. Novato, CA: Freeperson.

Criswell, E. \& Serlin, I. (2014). Humanistic psychology, mind/body medicine and whole person healthcare. In: Schneider, K., Pierson, J.F., \& Bugental, J.F.T. (Eds.), The handbook of humanistic psychology (pp. 27-40). Thousand Oaks, CA: Sage.

Frankl, V.E. (1984). Man's search for meaning (rev. and updated ed.). New York: Washington Square Press. Hanna, T. (1970). Bodies in revolt: A primer in somatic thinking. New York: Holt, Rinehart \& Winston.

Heidegger, M. (1962). Being and time (McQuarrie, J., \& Robinson, E., Trans.). New York: Harper \& Row. (Original published 1927).

Hoffman, L., Serlin, I.A., \& Rubin, S. (2019). The history of existential-humanistic and existential-integrative therapy. In: van Deurzen, E., Craig, E., Langle, A., Schneider, K.J., Tantam, D., \& du Plock, S. (Eds.), The Wiley world handbook of existential therapy (pp. 235-246). New York: John Wiley \& Sons.

Hoffman, L., Yang, M., Kaklauskas, F., \& Chan, A. (2009). Existential psychology East-West. Colorado Springs (CO): University of the Rockies Press.

Husserl, E. (1931). Ideas: General introduction to pure phenomenology (Gibson, W.R.B., Trans.). New York: Macmillan. (Original work published 1913).

Jaspers, K. (1956). Existenzphilosophie (Kaufmann, W., Trans.). In: Existentialism from Dostoevsky to Sartre (Kaufmann, W., Ed.) (pp. 138-252). London: Penguin Books. (Original work published 1941).

Jourard, S.M. (1976). Some ways of unembodiment and re-embodiment. Somatics, 1(1), 3-7.

Kierkegaard, S. (1980). The concept of anxiety (Thomte, R., Trans.). Princeton, NJ: Princeton University Press. (Original work published 1844).

Laban, R. (1971). The mastery of movement (3rd ed.). Boston, MA: Plays, Inc.

Leventhal, M. (2008, June). Transformation and healing through dance movement therapy: The challenge and imperative of holding the vision, American Journal of Dance Therapy, 30(1), 4-23.

Levy, F. (1992). Dance/movement therapy: A healing art (rev. ed.). New York: American Alliance for Health Physical.

Lu Xun (1961). Sudden notions. In: Xianyi, Y., \& Yang, G., Trans. and Ed., Lu Xun: Selected works, Vol. 1. (pp. 138-140). Beijing, China: Foreign Language Press. (Original work published 1921).

Koff-Chapin, D. (1996). Drawing out your soul: The touch drawing experience. Langley, WA: Center for Touch Drawing.

Maslow, A. (1954). Motivation and personality. New York: Harper \& Row.

May, R. (1967). Psychology and the human dilemma. New York: Van Nostrand.

May, R. (1975). The courage to create. New York: Bantam Books.

May, R., Angel, E., \& Ellenberger, H.R. (1958). Existence: A new dimension in psychiatry and psychology. Northvale, NJ: Jason Aronson.

Moon, B. (2011). Existential art therapy: The canvas mirror. Taiwan: Living Psychology Publishers.

Ricoeur, P. (1976). Interpretation theory: Discourse and the surplus of meaning. Fort Worth, TX: Texas Christian University Press.

Rogers, C.R. (1951). Client-centered therapy: It's current practice, implications, and theory. Boston: Houghton-Mifflin \& Co.

Rogers, C.R. (1961). On becoming a person. Boston: Houghton-Mifflin \& Co.

Serlin, I. (1992, Summer). Tribute to Laura Perls. Journal of Humanistic Psychology, 32(3), 57-66.

Serlin, I. (1993), Root images of healing in dance therapy. American Journal of Dance Therapy, 15(2), $65-76$. 
Serlin, I.A. (1996, Spring). Kinaesthetic imagining. Journal of Humanistic Psychology, 36(2), 25-33.

Serlin, I.A. (2012). The courage to move. In: Schwartz, S., Speiser, V.M., Speiser, P., \& Kossak, M. (Eds.), The arts and social change: The Lesley University experience in Israel (pp. 117-125). Zur Yigal, Israel: Porat Books.

Serlin, I. (2014). Kinesthetic imagining. In: Thompson, B.E., \& Neimeyer, R.A. (Eds.), Grief and the expressive arts: Practices for creating meaning. New York: Routledge. 116-119.

Serlin, I. (2019). Back to the future: A case study. In: Hoffman, L., Yang, M., Mansilla, M., Dias, J., Moats, M. \& Claypool, C., (Eds.). Existential psychology East-West, Vol. 2 (pp. 203-207): Colorado Springs, CO: University Professors Press.

Wang, X. (2019). An East-West dialogue: An outline of existential therapy development in China and related Asian countries. In: van Deurzen, E., Craig, E., Langle, A., Schneider, K., Tantam, D., \& du Plock, S. (Eds.), The Wiley world handbook of existential therapy (pp. 579-591). Hoboken, NJ: John Wiley \& Sons.

Yalom, I. (1985). The theory and practice of group psychotherapy. New York: Basic Books.

Yalom, I.D. (2012). Existential psychotherapy. Beijing: The Commercial Press.

包祖晓. (2019). 唤醒身体的自愈力. 台北: 大都会文化事业有限公司.

江光荣. (1999). 人性的迷失与富贵一罗杰斯的人本主义心理学. 武汉: 湖北教育出版社.

Yang, M.C. (Ed.). (2016). Existential psychology and the way of the Tao: Meditations on the writings of Zhuangzi. New York: Routledge.

Yang, M.C. (2017). Existential psychology and the way of the Tao: Meditations on the writings of Zhuangzi. New York: Routledge. 